\title{
NMR pseudocontact shifts in a symmetric protein homotrimer
}

\author{
Thomas Müntener ${ }^{1} \cdot$ Raphael Böhm $^{1} \cdot$ Kenneth Atz $^{1} \cdot$ Daniel Häussinger ${ }^{2} \cdot$ Sebastian Hiller $^{1}$ (i)
}

Received: 1 April 2020 / Accepted: 25 June 2020 / Published online: 3 July 2020

(c) The Author(s) 2020

\begin{abstract}
NMR pseudocontact shifts are a valuable tool for structural and functional studies of proteins. Protein multimers mediate key functional roles in biology, but methods for their study by pseudocontact shifts are so far not available. Paramagnetic tags attached to identical subunits in multimeric proteins cause a combined pseudocontact shift that cannot be described by the standard single-point model. Here, we report pseudocontact shifts generated simultaneously by three paramagnetic Tm-M7PyThiazole-DOTA tags to the trimeric molecular chaperone Skp and provide an approach for the analysis of this and related symmetric systems. The pseudocontact shifts were described by a "three-point" model, in which positions and parameters of the three paramagnetic tags were fitted. A good correlation between experimental data and predicted values was found, validating the approach. The study establishes that pseudocontact shifts can readily be applied to multimeric proteins, offering new perspectives for studies of large protein complexes by paramagnetic NMR spectroscopy.
\end{abstract}

Keywords Solution NMR spectroscopy $\cdot$ Pseudocontact shift $\cdot$ Paramagnetism $\cdot$ Lanthanide chelating tag $\cdot$ Homotrimer · Chaperone Skp

\section{Introduction}

Precise descriptions of protein structure and dynamics are key to understand biological functionality. NMR spectroscopy has proven a valuable source to gain such information under native or native-like conditions for highly relevant systems. Thereby, different geometrical restraints can be used to determine the structure of a protein. While residual dipolar couplings (RDCs) determine relative orientations of bond vectors (Chen and Tjandra 2012), nuclear Overhauser effects (NOEs) provide short-range distance information (Wagner and Wüthrich 1982; Williamson 2009). On the other hand, the two paramagnetic effects paramagnetic relaxation enhancement (PRE) and pseudocontact shift (PCS), which can be introduced into proteins by various

Electronic supplementary material The online version of this article (https://doi.org/10.1007/s10858-020-00329-7) contains supplementary material, which is available to authorized users.

Sebastian Hiller

sebastian.hiller@unibas.ch

1 Biozentrum, University of Basel, Klingelbergstrasse 70, 4056 Basel, Switzerland

2 Department of Chemistry, University of Basel, St. Johanns-Ring 19, 4056 Basel, Switzerland lanthanide-chelating tags (LCTs), have proven to provide valuable distance- and orientation-dependent information over extremely long distances exceeding $100 \AA$ A (Joss and Häussinger 2019a; Nitsche and Otting 2017; Wang et al. 2007; Bertini et al. 2002a,b; Gochin and Roder 1995; Pearce et al. 2017). LCTs based on the DOTA (1,4,7,10-tetraazacyclododecane-1,4,7,10-tetraacetic acid) framework provide large PCSs and are usually attached to the protein surface via one or two cysteine residues (Joss and Häussinger 2019a; Nitsche and Otting 2017; Keizers et al. 2007; Prudencio et al. 2004). Recent developments of LCTs with reductionstable linkages have enabled studies under physiologically relevant conditions in living cells (Müntener et al. 2016, 2018; Pan et al. 2016; Joss and Häussinger 2019b; Liu et al. 2014; Hikone et al. 2016). Nevertheless, many soluble proteins, as well as membrane proteins, form homomultimeric complexes (Hashimoto et al. 2011; Ali and Imperiali 2005; Goodsell and Olson 2000), which are not readily accessible by PCS NMR spectroscopy due to formation of multi-tagged protein complexes. Here, we report a generalized approach to study pseudocontact shift effects generated by multiple paramagnetic centers and demonstrate this approach on the homotrimeric protein Skp (Walton and Sousa 2004; Korndörfer et al. 2004; Burmann et al. 2013; Callon et al. 2014). 


\section{Methods and materials}

\section{Cloning and mutagenesis of Skp single-cysteine mutants}

The original Skp gene without its signal sequence was cloned from genomic DNA through NdeI and XhoI into the pET28b expression vector (Novagen) containing a thrombin-cleavable $\mathrm{N}$-terminal $\mathrm{His}_{6}$-tag (Burmann et al. 2013). The QuikChange II mutagenesis protocol (Stratagene) was used to introduce the mutation S126C. PCR primers were obtained from Microsynth.

\section{Expression, purification of Skp (S126C)}

Uniformly $\left[{ }^{2} \mathrm{H},{ }^{15} \mathrm{~N}\right]-\mathrm{Skp}(\mathrm{S} 126 \mathrm{C})$ was produced as previously described (Burmann et al. 2013). In brief, BL21(DE3)-LEMO cells (NEB) were transformed with the plasmid and grown at $37^{\circ} \mathrm{C}$ in $\mathrm{D}_{2} \mathrm{O}$-based $\mathrm{M} 9$ medium, with $1 \mathrm{~g}{ }^{15} \mathrm{~N}$-ammonium chloride, containing $30 \mathrm{mg} /$ $\mathrm{mL}$ kanamycin to $\mathrm{OD}_{600}=0.6$ and then for an additional $30 \mathrm{~min}$ at $20{ }^{\circ} \mathrm{C}$ before expression was induced with $0.4 \mathrm{mM}$ IPTG. Cells were harvested $18 \mathrm{~h}$ after induction, resuspended in lysis buffer (25 mM HEPES, $\mathrm{pH} 7.5$, $300 \mathrm{mM} \mathrm{NaCl}, 10 \mathrm{mM}$ imidazole, DNase $(0.01 \mathrm{mg} / \mathrm{mL})$, RNase $(0.02 \mathrm{mg} / \mathrm{mL})$ and inhibitor cocktail (cOmplete EDTA-free protease inhibitor, Roche) at a 4:1 buffer/pellet weight ratio and lysed by sonication. The soluble lysate was separated from cell debris and other components by centrifugation at $14^{\prime} 000 \times g$ for $60 \mathrm{~min}$ at $4{ }^{\circ} \mathrm{C}$ and then applied to $\mathrm{Ni}^{2+}$ beads (Genscript) equilibrated with lysis buffer. The wash buffer contained $30 \mathrm{mM}$ imidazole and the elution buffer $500 \mathrm{mM}$ imidazole. Skp(S126C) elution fractions were dialyzed against $25 \mathrm{mM}$ HEPES, $\mathrm{pH}$ $7.5,300 \mathrm{mM} \mathrm{NaCl}$ overnight at $4{ }^{\circ} \mathrm{C}$ to remove imidazole. The dialyzed Skp sample was denatured with $6 \mathrm{M}$ guanidinium hydrochloride, applied to $\mathrm{Ni}^{2+}$ beads, and eluted with $500 \mathrm{mM}$ imidazole. $10 \mathrm{mM}$ DTT were added to the Skp elution fraction before dialysis against lysis buffer containing $5 \mathrm{mM}$ DTT over night at $4{ }^{\circ} \mathrm{C}$. As a final purification step, $\mathrm{Skp}(\mathrm{S} 126 \mathrm{C})$ was buffer exchanged to NMR buffer (20 mM MES, pH 6.5, $150 \mathrm{mM} \mathrm{NaCl}$ and $1 \mathrm{mM}$ DTT) using size exclusion chromatography (Superdex200 16/600). Refolded Skp(S126C) eluted from a size exclusion column (HiLoad 16/600 Superdex $200 \mathrm{pg}$ ) at an elution volume of $79 \mathrm{~mL}$, which corresponds to trimeric wild-type Skp and is substantially different from monomeric wild-type Skp. A 2D $\left[{ }^{15} \mathrm{~N},{ }^{1} \mathrm{H}\right]$-TROSY spectrum was recorded to ensure that the S126C mutation had no effect on overall Skp structure. Just as for wild-type Skp (Burmann et al. 2013), the spectrum of the $\operatorname{Skp}(\mathrm{S} 126 \mathrm{C})$ mutant features a single resonance for each amide moiety, resulting from superimposition of the individual signals from the three promoters due to the molecular symmetry. Afterwards, Skp was either directly used for site-specific spin labeling or stored at $-20{ }^{\circ} \mathrm{C}$ until use.

\section{Site-specific spin labeling of Skp(S126C)}

Spin labeling with the lanthanide chelating tag, Tm-M7PyThiazol-DOTA, of the introduced cysteine S126C was done according to published protocols (Müntener et al. 2018). In brief, protein solution (100 $\mu \mathrm{M}$ Skp trimer) in NMR buffer was exchanged to tagging buffer $(50 \mathrm{mM}$ sodium phosphate, $\mathrm{pH} 7,150 \mathrm{mM} \mathrm{NaCl}, 0.3 \mathrm{mM}$ TCEP) in Vivaspin 5-kDa concentrators (Vivascience). A sevenfold excess of Tm-M7PyThiazol-DOTA dissolved in tagging buffer was added to the protein solution, and this was followed by incubation overnight at room temperature under shaking at $300 \mathrm{rpm}$. To remove unreacted Tm-M7PyThiazol-DOTA, the buffer was exchanged back to NMR buffer using 5-kDa concentrators.

\section{NMR measurements of Skp(S126C)}

All NMR spectra were recorded at $25{ }^{\circ} \mathrm{C}$ on a Bruker Avance-700 spectrometer equipped with a cryogenic triple-resonance probe. The sample contained $0.3-0.4 \mathrm{mM}$ $\left[{ }^{2} \mathrm{H},{ }^{15} \mathrm{~N}\right]$-labeled protein Skp in $20 \mathrm{mM}$ MES pH 6.5 with $150 \mathrm{mM} \mathrm{NaCl}, 1 \mathrm{mM}$ DTT and $5 \% / 95 \% \mathrm{D}_{2} \mathrm{O} / \mathrm{H}_{2} \mathrm{O}$. The proton chemical shifts were referenced to internal DSS and those for carbon-13 and nitrogen- 15 were indirectly referenced. The 2D $\left[{ }^{15} \mathrm{~N},{ }^{1} \mathrm{H}\right]$-TROSY and semi-TROSY were recorded in a total experiment time of $14 \mathrm{~h}$. The ${ }^{1} \mathrm{H}$ carrier was centered on the water resonance, the ${ }^{15} \mathrm{~N}$ carrier at $118 \mathrm{ppm}$. The interscan delay was set to $1 \mathrm{~s}$. In the direct dimension, 1024 complex points were recorded in an acquisition time of $90 \mathrm{~ms}$, multiplied with a $90^{\circ}$-shifted sine bell, zero-filled to 2048 points and Fourier transformed. In the indirect dimension, 200 complex points were measured with a maximal evolution time of $93 \mathrm{~ms}$, multiplied with a $90^{\circ}$-shifted sine bell, zero-filled to 512 points and Fourier transformed. Polynomial baseline corrections were applied in all dimensions.

\section{PCS tensor fitting}

Paramagnetic anisotropic susceptibility tensors were fitted using an in-house Python script. The source code is available upon request. 


\section{Results and discussion}

The PCS of a nuclear spin is the difference in chemical shift between the paramagnetic sample and a diamagnetic reference. The shift arises from dipolar through-space interaction between the nuclear spin and a paramagnetic center that has an anisotropic electron g-factor. Using the point-dipole approximation, the PCS caused by a single paramagnetic center can be described by the following expression (Bertini et al. 2002a):

$\sigma_{\mathrm{PCS}}=\frac{1}{12 \pi}\left[\Delta \chi_{\mathrm{ax}} \frac{2 z^{2}-x^{2}-y^{2}}{r^{5}}+\frac{3}{2} \Delta \chi_{\mathrm{rh}} \frac{x^{2}-y^{2}}{r^{5}}\right]$

where $\Delta \chi_{\mathrm{ax}}$ and $\Delta \chi_{\mathrm{rh}}$ are the axial and rhombic components of the anisotropy of the magnetic susceptibility tensor $\chi$, respectively, $r$ is the distance from the nucleus to the paramagnetic center and $x, y, z$ describe the Cartesian coordinates of the nucleus in the tensor frame. The tensor frame has the paramagnetic center at the origin and the axes oriented according to the symmetry of the PCS.

For a given three-dimensional protein structure and experimental pseudocontact shifts, the anisotropic part of the magnetic susceptibility tensor can be determined from a sufficiently large data set by fitting eight free parameters (Schmitz et al. 2008). These are $\Delta \chi_{\mathrm{ax}}$ and $\Delta \chi_{\mathrm{rh}}$, which describe the shape and size of the tensor, $x_{\text {metal }}, y_{\text {metal }}$ and $z_{\text {metal }}$, which define the position of the paramagnetic center in the molecular frame, and the three Euler angles $\alpha, \beta$ and $\gamma$, which define the relative orientation of the tensor frame with respect to the molecular frame.

For a system with multiple paramagnetic centers, the observed PCS is the sum of the individual PCS contributions generated by each paramagnetic center (Velyvis et al. 2009). The tensor frames of these individual centers are in general not aligned with respect to each other, resulting in the following expression:

$\sigma_{\mathrm{PCS}}=\sum_{i=1}^{n} \frac{1}{12 \pi}\left[\Delta \chi_{\mathrm{ax}_{i}} \frac{2 z_{i}^{2}-x_{i}^{2}-y_{i}^{2}}{r_{i}^{5}}+\frac{3}{2} \Delta \chi_{\mathrm{rh}_{i}} \frac{x_{i}^{2}-y_{i}^{2}}{r_{i}^{5}}\right]$

where $i$ indexes the individual paramagnetic tensors. In principle, this equation requires fitting of eight parameters for each paramagnetic center. Importantly, however, for symmetric systems the number of free parameters reduces substantially. For example, in the case of a homotrimeric protein with $\mathrm{C}_{3}$ symmetry, the three metal positions and the corresponding Euler angles are related by $120^{\circ}$ and $240^{\circ}$ rotations around the symmetry axis (Fig. 1). Furthermore, each of the three LCTs has identical $\Delta \chi_{\mathrm{ax}}$ and $\Delta \chi_{\mathrm{rh}}$ values.

Thus, a significant simplification can be achieved by realizing that the PCS generated by all three LCTs on a specific spin is the sum of all PCSs generated by one LCT

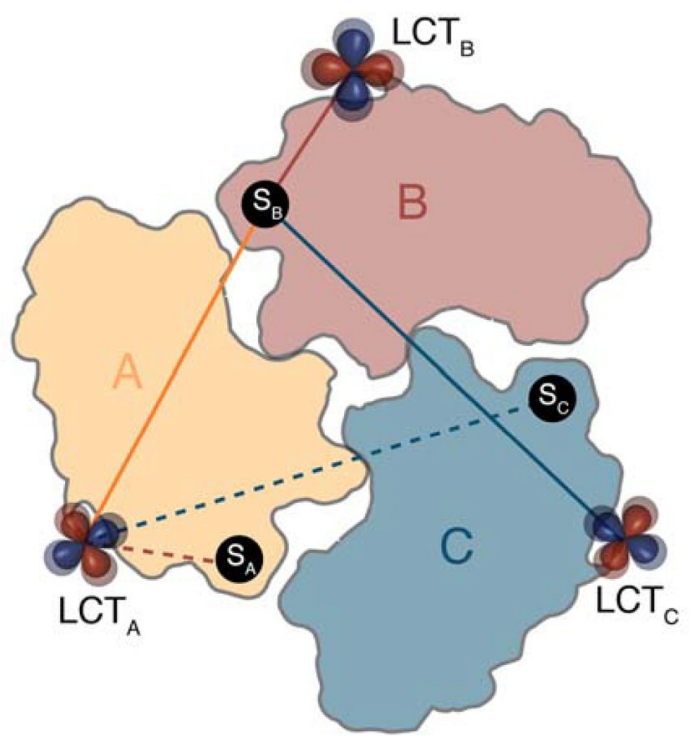

Fig. 1 Calculation of pseudocontact shifts in a symmetric homotrimer. The three symmetrically attached LCTs are labelled $\mathrm{LCT}_{\mathrm{A}-\mathrm{C}}$. In a $\mathrm{C}_{3}$ symmetric arrangement, the PCS effect experienced by spin $\mathrm{S}_{\mathrm{B}}$ generated by all LCTs is identical to the sum of all effects generated by a single LCT (e.g. $\mathrm{LCT}_{\mathrm{A}}$, dashed lines) on the symmetry equivalent spins $S_{A}, S_{B}$ and $S_{C}$

on all three symmetry equivalent spins in chains $\mathrm{A}, \mathrm{B}$ and C (Fig. 1). This property allows for a direct fitting procedure as only one set of eight free parameters describing one paramagnetic center needs to be calculated. Practically, the components of the anisotropy of the magnetic susceptibility tensor, the Euler angles, and one metal position can be fitted by minimizing a quadratic cost function $f$ using QuasiNewton methods implemented in the Python library SciPy:

$f=\sum_{j}\left[P C S_{j}^{\exp }-\left(P C S_{j_{A}}^{\text {calc }}+P C S_{j_{B}}^{\text {calc }}+P C S_{j_{C}}^{\text {calc }}\right)\right]^{2}$

where $j$ defines the nuclear spins and $A, B$ and $C$ denote the corresponding $\mathrm{C}_{3}$-symmetric chains. Notably, in a $\mathrm{C}_{3}$-symmetric environment, three different local minima of $f$ exist, each of which corresponds to the tag positioned on one of the three chains A, B or C. Changing the initial starting position of the iteration close to one of the chains provides access to all three possible solutions in three successive minimizations with the same input data.

We prepared uniformly labelled $\left[{ }^{2} \mathrm{H},{ }^{15} \mathrm{~N}\right]$-Skp with a single cysteine introduced at position $126(\mathrm{Skp}(\mathrm{S} 126 \mathrm{C}))$, following established protocols (Burmann et al. 2013). The cysteine mutation was specifically introduced into helix 5 , which is a stable structural element of Skp, providing good solvent accessibility and limited molecular motion. First, we prepared a diamagnetic reference sample using untagged $\left[{ }^{2} \mathrm{H},{ }^{15} \mathrm{~N}\right]-\mathrm{Skp}(\mathrm{S} 126 \mathrm{C})$. Second, we prepared a 


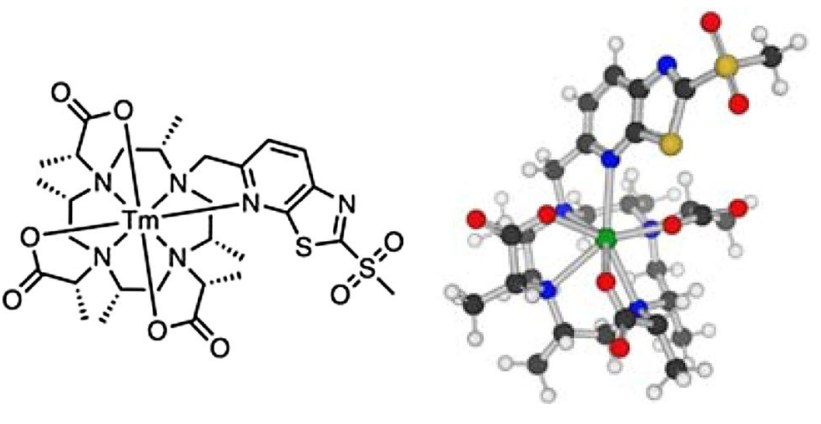

Fig. 2 2D representation and 3D Structure of Tm-M7PyThiazol- $\mathrm{SO}_{2}$ Me-DOTA

paramagnetically tagged $\left[{ }^{2} \mathrm{H},{ }^{15} \mathrm{~N}\right]-\mathrm{Skp}(\mathrm{S} 126 \mathrm{C})$ sample, using Tm-M7PyThiazole-SO $\mathrm{S}_{2}$-Me-DOTA. Thereby, the metal Tm was chosen, because it is among the three lanthanides showing the strongest shift (Tm, Dy, Tb). Furthermore, in the M7PyThiazole-SO $\mathrm{S}_{2}$-Me-DOTA tag, Tm has been shown to produce PCSs at more distant residues due to its more favorable orientation of the tensor isosurfaces, while exhibiting smaller PREs compared to Dy (Müntener et al. 2018). Tagging was performed overnight at room temperature using a sevenfold excess of the paramagnetic spin label at $\mathrm{pH} 7.0$ under reducing conditions. We recorded a 2D $\left[{ }^{15} \mathrm{~N},{ }^{1} \mathrm{H}\right]$-TROSY at $700 \mathrm{MHz}$ Larmor frequency and $25{ }^{\circ} \mathrm{C}$. For the non-shifted, diamagnetic reference spectrum, we observed only one single, coherent set of resonances and no significant chemical shift changes, in good agreement with previously reported data (Burmann et al. 2013). The paramagnetically shifted spectrum also exhibited one single and coherent set of resonances, indicating a highly selective and complete threefold tagging of Skp(S126C) by TmM7PyThiazole-SO $\mathrm{S}_{2}$-Me-DOTA (Fig. 2). The observed PCSs were mostly positive, reaching up to 5 ppm (Fig. 3). Notably, an incomplete tagging or disruption of the protein structure would break the $\mathrm{C}_{3}$ symmetry, leading to an asymmetric structure and resulting in tripling of the observed resonances (Gaponenko et al. 2002).

For further analysis of the observed PCSs, the aforementioned three-positions-one-tensor method was used. While the available crystal structures of Skp (PDB 1U2M, 1SG2) report only partly resolved polypeptide chains, the protein is known to exhibit fast dynamics in aqueous solution, leading to a complete symmetry equivalence of the three subunits on the NMR timescale (Burmann et al. 2013). This property allowed us to extend the incomplete regions of the crystal structure $1 \mathrm{U} 2 \mathrm{M}$ by duplicating the complete chain $\mathrm{A}$ and superimposing it on the incomplete parts of chain B and C. The modified structure features a complete set of atomic coordinates for all residues in all chains, and exhibits a slight asymmetry due to crystal contacts. Assignment of the diamagnetic reference spectrum was taken from the BMRB

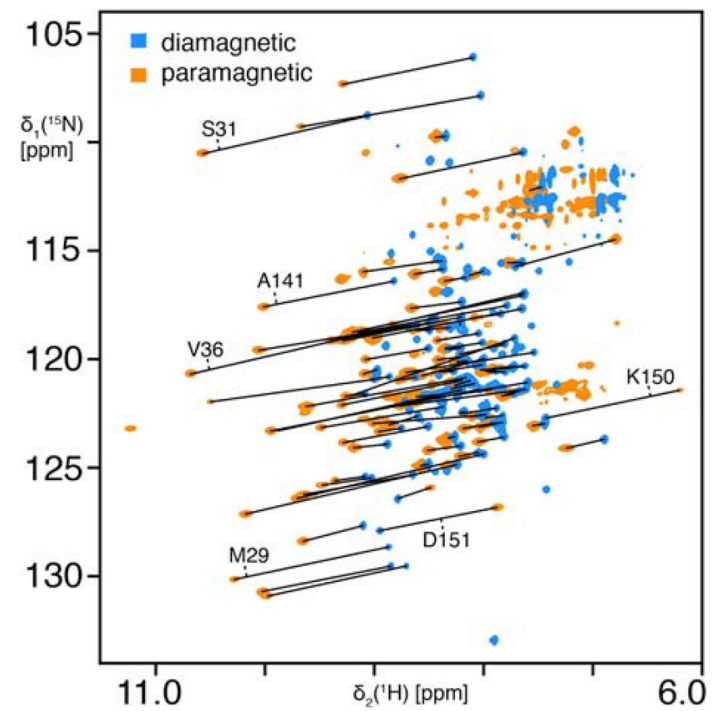

Fig. 3 NMR pseudocontact shifts in the homotrimeric protein Skp. Superposition of $2 \mathrm{D}\left[{ }^{15} \mathrm{~N},{ }^{1} \mathrm{H}\right]-\mathrm{TROSY}$ spectra of $\mathrm{Skp}(\mathrm{S} 126 \mathrm{C}$ ) (diamagnetic, blue) and coupled to paramagnetic Tm-M7Py-ThiazolDOTA (orange). Measured pseudocontact shifts are illustrated with a black line and a few selected residues are labelled with their assignment. Spectra were recorded in aqueous buffer $(25 \mathrm{mM}$ MES, $150 \mathrm{mM} \mathrm{NaCl}, \mathrm{pH} 6.5$ ) at $700 \mathrm{MHz}$ Larmor frequency and $25^{\circ} \mathrm{C}$

entry 19407 and the paramagnetic spectrum was assigned in an iterative fashion. An initial set of around ten unambiguous pseudocontact shifts were used to approximate the tensor. Back-prediction using this initial tensor values and the sequence-specific resonance assignment in the diamagnetic reference spectrum provided access to further assignments of the paramagnetic spectrum, which were used to refine the tensor. This procedure was repeated iteratively until no further assignments were possible. The tensor parameters converged with the input data from around 40 PCSs and stayed stable upon inclusion of the data from all other residues.

Table 1 PCS tensor parameters of trimeric $\operatorname{Skp}(\mathrm{S} 126 \mathrm{C})$ with three Tm-M7PyThiazol-DOTA tags

\begin{tabular}{lccc}
\hline & Chain A & Chain B & Chain C \\
\hline$\Delta \chi_{\text {ax }}\left(10^{-32} \mathrm{~m}^{3}\right)$ & -43.0 & -42.2 & -43.0 \\
$\Delta \chi_{\text {rh }}\left(10^{-32} \mathrm{~m}^{3}\right)$ & -7.8 & -8.5 & -8.5 \\
$\mathrm{r}_{\text {metal }}(\AA)^{\mathrm{a}, \mathrm{c}}$ & 25.1 & 25.5 & 25.6 \\
$\theta_{\text {metal }}\left({ }^{\circ}\right)^{\mathrm{a}, \mathrm{c}}$ & 241.0 & 0.0 & 121.0 \\
$\alpha\left({ }^{\circ}\right)^{\mathrm{b}, \mathrm{c}}$ & 96.0 & 93.9 & 91.0 \\
$\beta\left(\left(^{\circ}\right)^{\mathrm{b}, \mathrm{c}}\right.$ & 120.3 & 63.01 & 63.5 \\
$\gamma\left(\left(^{\circ}\right)^{\mathrm{b}, \mathrm{c}}\right.$ & 71.7 & 132.3 & 6.5 \\
\hline
\end{tabular}

${ }^{\mathrm{a}}$ Metal position given in polar coordinates

' Euler angles given in 'ZYZ' convention

${ }^{\mathrm{c}}$ Coordinates have been rotated such that the origin $(0,0,0)$ is in the center of gravity of the three metals and all metals lie in the xy-plane 
Three different sets of tensor parameters were fitted using different starting positions for the metal corresponding to the three attachment sites of the spin-label (Table 1). The obtained tensor parameters are remarkably similar and show only small deviations, which are well explained by the lack of a perfect $\mathrm{C}_{3}$ symmetry in the crystal structure. As can be seen from the almost identical tensor parameters, the three metals form a near-perfect equilateral triangle with average distances of 5.5-6.2 $\AA$ to the corresponding $\mathrm{C}^{\alpha}$ atom of cysteine C126 (Fig. 4a).

Paramagnetic alignment induced sizeable RDCs reaching absolute magnitudes of up to $40 \mathrm{~Hz}$ at $700 \mathrm{MHz}$ Larmor frequency (SI Table 2) and in addition, residual anisotropic chemical shifts (RACS) are to be expected. We analyzed the effect of partial alignment on the quality of the fit and the tensor parameters by using only proton PCS for which the errors on our observed PCS can be neglected as both contributions from RACS (John et al. 2005) and RDCs are small. We found only marginal changes in the quality of the fit and the tensor parameters and as a consequence all measured PCS were used.

Upon close inspection we found that experimental PCSs are in good agreement with the back-calculated values. Larger deviations occurred in regions previously identified to undergo large backbone motions (Fig. 4b, c) (Burmann et al. 2013). A number of resonances in close proximity to the tagging sites are line-broadened beyond the detection limit due to the PRE effect (Figure S3). The three LCTs generate overlapping isosurfaces resulting in a propeller-like shape and a significantly larger positive isosurface covering a large portion of the arms of Skp (Fig. 4d). These extended isosurfaces allow in favorable cases the study of structural changes in remote distances greater than $100 \AA$ away from the tagging site.

\section{Conclusion}

In conclusion, we derived a generalised approach for the interpretation and analysis of PCS generated by multiple symmetric paramagnetic centers. We also established a substantially simplified procedure for fitting of the tensor parameters, which is readily extendable to any $C_{n}$ symmetric system. On the homotrimeric protein Skp we demonstrated the feasibility of measuring PCS with three attached LCTs. The applied model resulted in good agreement between experimental and back-calculated PCS, showing larger deviations in highly dynamic regions. We envision that the irreversible linkage between the protein and the LCT in combination with the method reported herein will allow the
A

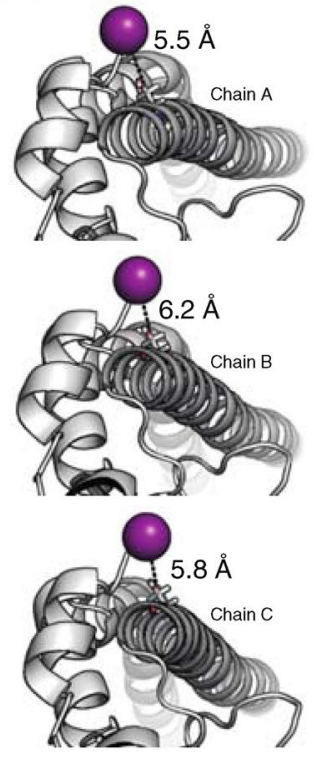

\section{B}

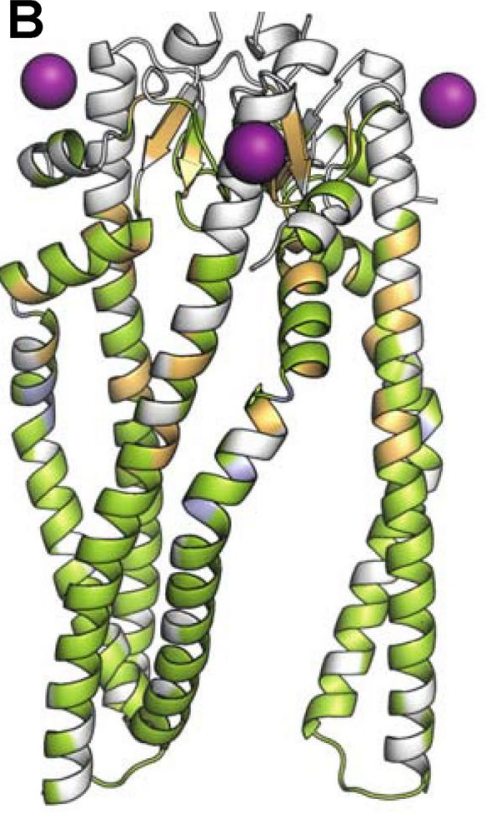

C

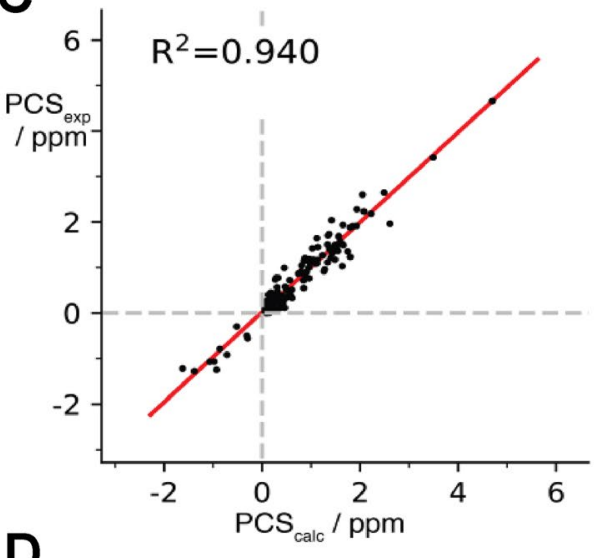

D
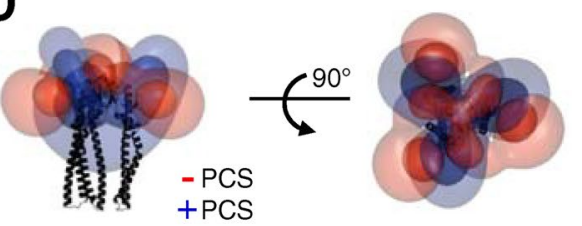

Fig. 4 NMR pseudocontact shifts in $\mathrm{Skp}(\mathrm{S} 126 \mathrm{C})$. a Location of the three fitted LCT positions (purple spheres) for chains A-C. The distance to the corresponding Cys $\mathrm{C}^{\beta}$ is indicated by a dashed line. $\mathbf{b}$ Display of PCS deviations on the structure of Skp. Residues with a total PCS deviation of less than $0.2 \mathrm{ppm}$ are colored in green. Residues in orange or blue have a deviation of larger $0.2 \mathrm{ppm}$ or $0.4 \mathrm{ppm}$, respectively. Unassigned residues are colored in gray. The metal positions of the LCTs are indicated as purple spheres. c Correlation graph between PCSs back calculated from the modified X-ray structure and the experimental PCS tabulated in Table S1. d Isosurfaces generated by three Tm loaded M7PyThiazol-DOTA tags coupled to $\operatorname{Skp}(\mathrm{S} 126 \mathrm{C})$. Red isosurfaces indicate a shift of $-1.0 /-0.2 \mathrm{ppm}$ (inner/outer surface). Blue isosurfaces indicate a corresponding positive shift 
study of large biologically relevant homomultimeric systems under physiological conditions, providing valuable insights into their long-range structure, interactions and dynamics.

Acknowledgements We thank Peter Bond and Daniel Holdbrook for discussions.

Funding This research was funded by the Swiss National Science Foundation (Grant 310030B_185388 to S.H.). No competing financial interests have been declared.

Availability of data and material The Supporting Information is available free of charge on the Publications website.

Code availability Python source code is available upon request.

\section{Compliance with ethical standards}

Conflict of interest The authors declare that they have no conflict of interest.

Open Access This article is licensed under a Creative Commons Attribution 4.0 International License, which permits use, sharing, adaptation, distribution and reproduction in any medium or format, as long as you give appropriate credit to the original author(s) and the source, provide a link to the Creative Commons licence, and indicate if changes were made. The images or other third party material in this article are included in the article's Creative Commons licence, unless indicated otherwise in a credit line to the material. If material is not included in the article's Creative Commons licence and your intended use is not permitted by statutory regulation or exceeds the permitted use, you will need to obtain permission directly from the copyright holder. To view a copy of this licence, visit http://creativecommons.org/licenses/by/4.0/.

\section{References}

Ali MH, Imperiali B (2005) Protein oligomerization: how and why. Bioorg Med Chem 13:5013-5020

Bertini I, Luchinat C, Parigi G (2002a) Magnetic susceptibility in paramagnetic NMR. Prog Nucl Magn Reson Spectrosc 40:249-273

Bertini I, Luchinat C, Parigi G (2002b) Paramagnetic constraints: an aid for quick solution structure determination of paramagnetic metalloproteins. Concepts Magn Reson 14:259-286

Burmann BM, Wang C, Hiller S (2013) Conformation and dynamics of the periplasmic membrane-protein-chaperone complexes OmpXSkp and tOmpA-Skp. Nat Struct Mol Biol 20:1265-1272

Callon M, Burmann BM, Hiller S (2014) Structural mapping of a chaperone-substrate interaction surface. Angew Chem Int Ed 53:5069-5072

Chen K, Tjandra N (2012) The use of residual dipolar coupling in studying proteins by NMR. Top Curr Chem 326:47-67

Gaponenko V, Altieri AS, Li J, Byrd RA (2002) Breaking symmetry in the structure determination of (large) symmetric protein dimers. J Biomol NMR 24:143-148

Gochin M, Roder H (1995) Protein structure refinementbased on paramagnetic NMR shifts: applications to wild-type and mutant forms of cytochrome c. Protein Sci 4(2):295-305

Goodsell DS, Olson AJ (2000) Structural symmetry and protein function. Annu Rev Biophys Biomol Struct 29:105-153
Hashimoto K, Nishi H, Bryant S, Panchenko AR (2011) Caught in selfinteraction: evolutionary and functional mechanisms of protein homooligomerization. Phys Biol 8:035007

Hikone Y, Hirai G, Mishima M, Inomata K, Ikeya T, Arai S, Shirakawa M, Sodeoka M, Ito Y (2016) A new carbamidemethyl-linked lanthanoid chelating tag for PCS NMR spectroscopy of proteins in living HeLa cells. J Biomol NMR 66:99-110

John M, Park AY, Pintacuda G, Dixon NE, Otting G (2005) Weak alignment of paramagnetic proteins warrants correction for residual CSA effects in measurements of pseudocontact shifts. J Am Chem Soc 127:17190-17191

Joss D, Häussinger D (2019a) Design and applications of lanthanide chelating tags for pseudocontact shift NMR spectroscopy with biomacromolecules. Prog Nucl Magn Reson Spectrosc 114:284-312

Joss D, Häussinger D (2019b) P4T-DOTA—a lanthanide chelating tag combining a sterically highly overcrowded backbone with a reductively stable linker. Chem Commun 55:10543-10546

Keizers PH, Desreux JF, Overhand M, Ubbink M (2007) Increased paramagnetic effect of a lanthanide protein probe by two-point attachment. J Am Chem Soc 129:9292-9293

Korndörfer IP, Dommel MK, Skerra A (2004) Structure of the periplasmic chaperone Skp suggests functional similarity with cytosolic chaperones despite differing architecture. Nat Struct Mol Biol 11:1015-1020

Liu WM, Skinner SP, Timmer M, Blok A, Hass MA, Filippov DV, Overhand M, Ubbink M (2014) A two-armed lanthanoid-chelating paramagnetic NMR probe linked to proteins via thioether linkages. Chem Eur J 20:6256-6258

Müntener T, Häussinger D, Selenko P, Theillet FX (2016) In-cell protein structures from 2D NMR experiments. J Phys Chem Lett 7:2821-2825

Müntener T, Kottelat J, Huber A, Häussinger D (2018) New lanthanide chelating tags for PCS NMR spectroscopy with reduction stable, rigid linkers for fast and irreversible conjugation to proteins. Bioconjug Chem 29:3344-3351

Nitsche C, Otting G (2017) Pseudocontact shifts in biomolecular NMR using paramagnetic metal tags. Prog Nucl Magn Reson Spectrosc 98-99:20-49

Pan BB, Yang F, Ye Y, Wu Q, Li C, Huber T, Su XC (2016) 3D structure determination of a protein in living cells using paramagnetic NMR spectroscopy. Chem Commun 52:10237-10240

Pearce BJG, Jabar S, Loh CT, Szabo M, Graham B, Otting G (2017) Structure restraints from heteronuclear pseudocontact shifts generated by lanthanide tags at two different sites. J Biomol NMR 68:19-32

Prudencio M, Rohovec J, Peters JA, Tocheva E, Boulanger MJ, Murphy ME, Hupkes HJ, Kosters W, Impagliazzo A, Ubbink M (2004) A caged lanthanide complex as a paramagnetic shift agent for protein NMR. Chemistry 10:3252-3260

Schmitz C, Stanton-Cook MJ, Su XC, Otting G, Huber T (2008) Numbat: an interactive software tool for fitting $\Delta \chi$-tensors to molecular coordinates using pseudocontact shifts. J Biomol NMR 41:179-189

Velyvis A, Schachman HK, Kay LE (2009) Assignment of Ile, Leu, and Val methyl correlations in supra-molecular systems: an application to aspartate transcarbamoylase. J Am Chem Soc 131:16534-16543

Wagner G, Wüthrich K (1982) Sequential resonance assignments in protein ${ }^{1} \mathrm{H}$ nuclear magnetic resonance spectra. Basic pancreatic trypsin inhibitor. J Mol Biol 155:347-366

Walton TA, Sousa MC (2004) Crystal structure of Skp, a prefoldinlike chaperone that protects soluble and membrane proteins from aggregation. Mol Cell 15:367-374 
Wang X, Srisailam S, Yee AA, Lemak A, Arrowsmith C, Prestegard JH, Tian F (2007) Domain-domain motions in proteins from timemodulated pseudocontact shifts. J Biomol NMR 39:53-61

Williamson MP (2009) Chapter 3 applications of the NOE in molecular biology. Annual reports on NMR spectroscopy, vol 65. Academic Press, Amsterdam, pp 77-10965
Publisher's Note Springer Nature remains neutral with regard to jurisdictional claims in published maps and institutional affiliations. 